\title{
Home assessment of visual working memory in pre- schoolers reveals associations between behaviour, brain activation and environmental measures.
}

Courtney McKay ${ }^{a}$, Yee Lee Shing ${ }^{b}$, Eva Rafetseder ${ }^{a}$, Sobanawartiny Wijeakumar ${ }^{c}$

a. Psychology, Faculty of Natural Sciences, University of Stirling, Scotland, United Kingdom

b. Institute of Psychology, Goethe University Frankfurt, Germany

c. School of Psychology, University of Nottingham, Nottingham, United Kingdom

${ }^{*}$ Correspondence should be addressed to Sobanawartiny Wijeakumar, School of Psychology, University of Nottingham, NG7 2RD, United Kingdom (email: sobanawartiny.wijeakumar@nottingham.ac.uk).

\section{Acknowledgements:}

We would like to thank all the children and their parents who participated, as well as the schools and nurseries who distributed our study information. We would also like to thank Ana Rozman, Amy Hanson, and Megan Everts who were instrumental in helping to collect the data.

The SAND project was funded by a Jacobs Foundation Research Fellowship to $Y$. L. Shing (JRF 2018-2020) and by a match-funded Ph.D. studentship from the University of Stirling. The work of Y. L. Shing is also supported by the European Union (ERC-2018-StG-PIVOTAL-758898).

No potential conflict of interest is reported by the authors.

The data that support the findings of this study are available from the corresponding author upon reasonable request. 
HOME ASSESSMENT OF VISUAL WORKING MEMORY

\title{
Research highlights
}

- Home-assessment of behaviour-brain measures of visual working memory.

- Low-performing children showed increasing activation with increasing load.

- High-performing children showed no difference in activation across loads.

- Right parietal cortex mediated the association between life stress and behaviour.

\begin{abstract}
Visual working memory (VWM) is reliably predictive of fluid intelligence and academic achievements. The objective of the current study was to investigate the nature of individual differences in pre-schoolers by examining the relationship between behaviour-brain function underlying VWM processing and parent-reported measures. We used a portable $8 \times 8$ channel functional near-infrared spectroscopy system to record from the frontal and parietal cortices of 4.5 -year-old pre-school children $(\mathrm{N}=74)$ as they completed a colour change detection VWM task in their homes. Parents were asked to fill in questionnaires on temperament, academic aspirations, home environment, and life stress. Children were median-split into a low-performing (LP) and a high-performing (HP) group based on the number of items they could successfully remember during the task. LPs increasingly activated the bilateral frontal and parietal cortices with increasing load, whereas HPs showed no difference in activation across the loads. Our findings suggested that LPs recruited more neural resources when their VWM capacity was challenged. We employed mediation analyses to examine the association between the difference in activation between the highest and lowest loads, and variables from the questionnaires. The difference in activation in the right parietal cortex partially mediated the association between parentreported stressful life events and VWM performance. Specifically, a higher number of stressful events was associated with lower VWM performance. Critically, our findings show that the association between VWM capacity, right parietal activation, and indicators of life stress is important to understand the nature of individual differences in VWM in pre-school children.
\end{abstract}


HOME ASSESSMENT OF VISUAL WORKING MEMORY

\section{Keywords:}

Visual Working Memory; Home testing; fNIRS; Individual differences; Life stress; Preschool children.

\section{Introduction}

Visual working memory (VWM) is a short-term storage system responsible for detecting changes in the world as they occur. VWM capacity is reliably predictive of cognitive functions (Fukuda et al., 2010) and a host of academic skills (Alloway and Alloway, 2010; Bull and Scerif, 2001; Gathercole et al., 2004; Swanson and BeebeFrankenberger, 2004). Critically, it accounts for around $40 \%$ of individual differences in global fluid intelligence (Fukuda et al., 2010), and for up to $46 \%$ of individual differences in performance on a cognitive battery of tasks (Johnson et al., 2013).

A common task for assessing VWM is the change-detection (CD) task (Luck and Vogel, 1997), where subjects are consecutively presented items and asked to identify if the items were identical across presentations. This task is particularly wellsuited for examining developmental trends, as age-related changes in capacity can be captured by varying the number of presented items. Using this task, Simmering (2012) found three-year-olds had a capacity of 1.5 to 2 items, increasing to 2 to 3 items by age five. This finding was confirmed by Buss and colleagues (2014), who found that three-year-old children had a capacity of 1.2 items while four-year-old children had a capacity of 1.8 items. While behavioural studies have provided insights into the capacity limitations of VWM, a more thorough understanding of the mechanisms underlying this system requires an understanding of underlying brain function.

Previous neuroimaging work on adults has consistently highlighted a distributed network of frontal and parietal regions in VWM processing. VWM capacity is associated with activity in the posterior parietal and superior occipital cortices, with activation increasing as the number of array-items increases, and reaching asymptote at maximum capacity (Todd and Marois, 2004). Activity in the posterior parietal cortex has been shown to predict individual differences in capacity in adults (Todd and Marois, 2005). Further, load-dependent responses have been found in the right intra- 
HOME ASSESSMENT OF VISUAL WORKING MEMORY

parietal sulcus and the right superior intraparietal sulcus (Ambrose et al., 2016). Koenigs and colleagues (2009) assessed a wide range of memory functions in patients with lesions in either hemisphere of the superior parietal cortex and found that this area was directly involved in the manipulation and re-arrangement of information for both auditory-verbal and visuospatial stimuli. Separately, another body of research has shown that the prefrontal cortex (PFC) is responsible for maintaining and encoding representations of task-relevant information into working memory (Baddeley, 2003; Miller and Cohen, 2001). Increased activation has been reported in the PFC during working memory tasks in both humans (Courtney et al., 1998) and non-human primates (Funahashi et al., 1993; Fuster and Alexander, 1971; Wilson et al., 1993). Postle (2006) argues working memory arises from the coordinated recruitment of several brain systems. Under this view, the activation of the PFC does not imply temporary storage of information, but rather, the focus of attention to relevant sensory systems where information is maintained. Along a similar vein, Christophel and colleagues (2017) proposed working memory relies on the interplay between sensory regions in the posterior cortex that retain low-level features and frontal regions that retain more abstract stimuli that are gradually transformed to an appropriate behavioural response. Taken together, these findings suggest that working memory emerges from a coordinated system involving a distributed network of brain regions across posterior and anterior cortices.

While fMRI studies have provided valuable insights into the neural processes underlying VWM in adults, there are limitations in its application in early development. fMRI scanners are noisy, and participants are required to lie still, an obstacle for young children. Recently, early developmental researchers have employed an alternative technique - functional near-infrared spectroscopy (fNIRS). fNIRS systems shine nearinfrared light (ranging from 650nm-1000nm) through the head to detect changes in oxygenated haemoglobin [HbO] and deo-oxygenated haemoglobin [HbR] (Boas et al., 2014). fNIRS is restricted to studying cortical brain areas, as near-infrared light only penetrates up to $2 \mathrm{~cm}$ into the brain. However, this limitation is less pronounced in children due to their smaller brains and thinner skulls (Buss et al., 2014). fNIRS has also been reliably used across the lifespan to study changes in activation in the frontal and parietal networks underlying VWM (Buss et al., 2014; Sato et al., 2013; Wijeakumar et al., 2019, 2017a, 2017b). 
HOME ASSESSMENT OF VISUAL WORKING MEMORY

Using fNIRS, Tsujimoto and colleagues (2004) examined VWM performance on a CD task in a sample of adults and five-year-old children. They found that activity in the bilateral areas of the PFC was similar in both groups, characterised by an increase in $\mathrm{HbO}$ with the onset of the memory array. These results demonstrated for the first time that the left PFC is also involved in VWM in pre-schoolers. Another fNIRS study examining VWM using the CD task in three- and four-year-old children found a more robust activation in the parietal cortex in four-year-olds relative to three-yearolds (Buss et al., 2014). However, in contrast to what has been consistently found in the adult literature, the haemodynamic response did not reach asymptote at maximum capacity - suggesting this neural asymptote effect may develop only after four years of age. Another study used a portable fNIRS system to investigate the neural networks underlying VWM processing in infants and children in rural India. They found that VWM performance was inversely correlated with activation in the bilateral frontal cortices, such that increased activation in this area was associated with poorer VWM performance (Wijeakumar et al., 2019). This study highlights another crucial advantage of fNIRS over other neuroimaging modalities - its portability, allowing researchers to freely explore cognitive processes outside of a traditional lab setting.

Individual differences in the development of VWM are predictive of subsequent academic achievements such as math abilities (Bull, Espy, \& Wiebe, 2008) and reading comprehension (Swanson and Berninger, 1996). Capacity limitations in VWM have also been linked to various developmental disorders including autism (Alloway et al., 2016) and attention-deficit hyperactivity disorder (Ferreira et al., 2015). Individual differences might stem from aspects of the child's home environment, temperament, parental aspirations, and life stress (Farah et al., 2006; Jeynes, 2005; Studer-Luethi et al., 2016; Wolfe and Bell, 2004). Thus, there is a clear need for researchers to establish the relationship between VWM performance and brain activation, and how this relates to the home environment and parental factors. The primary objective of the current study was to investigate the nature of individual differences in VWM behavioural performance and brain activation. We recruited a specific group of pre-schoolers born in either January or February 2014 which ensured minimal age variance and allowed us to investigate individual differences during the critical period before children begin formal education. Further, we explored the association between key behaviour and brain measures with variables from parent- 
HOME ASSESSMENT OF VISUAL WORKING MEMORY

reported measures of the home environment to better understand the role of the activated brain areas. We hypothesized that overall, performance would decrease as load increased. Critically, we expected that low-performing children would need to recruit greater neural resources, and as a result would elicit more activation than highperforming children, as VWM load increased.

\section{Methods}

Participants:

Ninety-five 4.5-year-olds (45 females, Mage $=53.5$ months, $S D=1.2$ ) participated in the study. Additionally, one of the parents of each child also took part in the study by filling out a series of questionnaires. We recruited participants by contacting gateway organizations such as nurseries and leisure centres and providing them with our study information. Parents of eligible children got in touch with us via our website, email, or over the phone to schedule a testing session. All participants resided in central Scotland (see Fig.1). Children received a small honorarium and gift for participation. All participants had normal or corrected to normal vision, no history of colourblindness, no neurological conditions, and all mothers experienced a close to full-term pregnancy (37 to 42 weeks) with an uncomplicated birth. Parents gave written informed consent and children gave verbal assent prior to testing. The research was approved by the General University Ethics Panel (GUEP 375) at the University of Stirling.

Data from twenty-one children had to be excluded from analyses; five children refused to participate in the task, twelve children interfered with the neuroimaging setup (pulled the cap off) before the completion of the task, two children had thick hair that prevented contact between the optodes and the scalp, and data from two children was lost due to experimenter error. A total of 74 children (37 females, Mage $=53.5$ months, $S D=1.3$ ) contributed to the final analyses.

Experimental task: 
HOME ASSESSMENT OF VISUAL WORKING MEMORY

The colour change-detection task (Simmering, 2012) was used to measure VWM performance in children. The task was explained using $3 \times 3$ inch flashcards with coloured squares, to ensure children understood the rules. The experimenter placed the first card (with one coloured square) on the table for approximately 2 seconds and asked the child to remember the card. The experimenter, then, turned over the first card and placed a second card (with one square of the same or different colour) on top. The child was asked if the two cards were the same or different. Once the child responded, the experimenter turned over both cards and praised the child if they had correctly answered the question and corrected them if they had given the wrong answer. This practice session was repeated with flashcards containing two and then, three coloured squares. The flashcards were displayed again if the child made a mistake. Once children had correctly answered the practice trials, the task was run in E-prime V. 3 software on an HP laptop with a 14 -inch screen. The computer task began with three practice trials, the first trial contained one square, the second contained two squares, and the third contained three squares. Children were corrected if they made a mistake before commencing the experimental trials. Each trial of the experimental task began with a memory array of coloured squares presented for 2 seconds, followed by a delay of 1 second, and finally, by the test array of coloured squares (see Fig. 2). The test array remained on the screen until a response was made. An intertrial interval of 1 second $(50 \%)$, 3s $(25 \%)$, or $5 \mathrm{~s}(25 \%)$ was used at the end of each trial. During 'same' trials, the colours in both arrays were identical. During 'different' trials, the colour of one square in the test array was different from the otherwise identical memory array. At the end of each trial, the experimenter asked the child if the two cards were the same or different. Children gave a verbal response, which the experimenter recorded on the laptop. During every trial, the memory and test arrays were presented one after another, occupying the same position on the screen. To prevent a bias towards one side, the arrays were randomly presented on either side of the screen. VWM load was manipulated from 1 to 3 square items (load 1, load 2, and load 3). Each load was presented in a block consisting of randomised presentations of 8 same and 8 different trials.

fNIRS data acquisition: 
HOME ASSESSMENT OF VISUAL WORKING MEMORY

fNIRS data were collected at $7.81 \mathrm{~Hz}$ using a NIRSport system 88 (8 sources 8 detectors) / release 2.01 with wavelengths of 850 and $760 \mathrm{~nm}$. Fiber optic cables carried light from the machine to a NIRS cap. Probe geometry was designed by collating regions of interest (ROI) from previous fMRI and fNIRS VWM literature (Wijeakumar et al., 2015). Probe geometry consisted of four channels each on the left and right frontal cortices, and three channels each on the left and right parietal cortices (see Fig. 3). Note that short-source-detector channels were not used to regress scalp hemodynamics as all the channels were directed toward maximising coverage of the frontal and parietal cortices. Four cap sizes $(50 \mathrm{~cm}, 52 \mathrm{~cm}, 54 \mathrm{~cm}$, and $56 \mathrm{~cm})$ were used to accommodate different head sizes. To synchronise behavioural and fNIRS data, a McDaq data acquisition device (www.mccdaq.com) was used to send information from the task presentation laptop to the fNIRS system. The trigger was sent at the start of each memory array.

\section{Procedure:}

We collected data from children in their homes which allowed us to move away from a traditional lab setting. Two researchers were present during each testing session. One researcher was responsible for checking the quality of the fNIRS signals, while the other researcher attended to the child and parent. We requested all children to sit on a chair at a table to make sure that all the equipment could be safely secured. The child's head circumference was measured so that the researchers could select the appropriately sized fNIRS cap. Once the cap was fitted to the child's head, measurements were taken from the inion to the nasion, and from the two peri-auricular points to make sure that the cap was centred. Children were given an iPad to watch cartoons during the set-up process. Once the set-up was complete (approx. 15 minutes, see Fig. 4), the experimenter began the session by introducing the task as "the colour game" and explained the rules using the flashcards. Children were then told they were going to play the same game on the computer. Children were rewarded with stickers throughout the session to maintain their motivation.

Parental Questionnaires: 
HOME ASSESSMENT OF VISUAL WORKING MEMORY

Parents were given a booklet of questionnaires to complete. Information regarding the scoring of the questionnaires can be found in the following references. The booklet included the Strengths and Difficulties Questionnaire (Goodman, 1997), the Parent Daily Hassles scale (Crnic and Booth, 1991; Crnic and Greenberg, 1990), the Family Activity Scale (from the Department of Health, Cox \& Bentovim, 2000), Parent and Teacher Involvement Questionnaire (derived from Conduct Problems Prevention Research Group), the Confusion, Order and Hubbub Scale (Matheny et al., 1995), the Parenting Stress Index (Abidin et al., 2013), and a socio-economic scale that assessed income, education and parental aspirations. For a detailed list of subscores, see Supplementary Table 1.

Data analyses:

Behavioural analyses:

Accuracy $\left(A^{\prime}\right)$ and capacity $(K)$ was calculated from hits $(H)$ and false alarms (FA) based on the behavioural responses. A' was calculated using Grier's (1971) formula, updated by Aaronson \& Watts (1987), where $A^{\prime}=1$ indicates perfect performance, and $A^{\prime}=0.5$ indicates chance performance.

If $H \geq F A: A^{\prime}=1 / 2+\left\{[(H-F A) *(1+H-F A)] /\left[4{ }^{*} H^{*}(1-F A)\right]\right\}$

If $\mathrm{H}<\mathrm{FA}: \mathrm{A}^{\prime}=1 / 2-\left\{\left[(\mathrm{FA}-\mathrm{H}){ }^{*}(1+\mathrm{FA}-\mathrm{H})\right] /\left[4^{*} \mathrm{FA}\right.\right.$ * $\left.\left.(1-\mathrm{H})\right]\right\}$

As demonstrated in Simmering (2016), for the cases where $\mathrm{H}$ and FA were equal to each other, accuracy was set to 0.5 .

K was calculated for each load using Pashler's (1988) formula:

$\mathrm{K}=\operatorname{Load}^{*}(\mathrm{H}-\mathrm{FA}) /(1-\mathrm{FA})$

Maximum $\mathrm{K}$ was estimated as the highest $\mathrm{K}$ value across all loads.

Pre-processing fNIRS signals:

fNIRS data were pre-processed using the Homer2 package (https://www.nitrc.org/projects/homer2/). Raw data were pruned using the 
HOME ASSESSMENT OF VISUAL WORKING MEMORY

enPrunechannels function (SNRthresh=2, SDrange $=0-45$ ). Signals were converted from intensity values to optical density (OD) units using the Intensity2OD function. Data was corrected for motion using the hmrMotionCorrectPCArecurse function, (tMotion=1, tMask=1, STDEVthresh=50, AMPthresh=0.5, nSV=0.97, maxlter=5, turnon=1). Data was scanned for motion artifacts using hmrMotionArtifactByChannel function (tMotion=1, tMask=1, STDEVthresh=50, AMPthresh=0.5). Then, the function enStimRejection (tRange $=-1$ to 10 ) was used to turn off stimulus triggers during any segments that contained motion artifacts. The data were band-pass filtered using hmrBandpassFilt to include frequencies between $0.016 \mathrm{~Hz}$ and $0.5 \mathrm{~Hz}$. Using the function hmrOD2Conc, the OD units were converted to concentration units. Lastly, the function hmrBlockAvg was used to calculate the block average for a time window of 1 to 12 seconds.

fNIRS group analyses:

Only correct trials were included in the fNIRS group analyses. We classified the hemodynamic response into an 'early phase' (3rd to 6th seconds), and a 'late phase' (6th to 9th seconds). These time windows were selected based on similar durations by Buss and colleagues (2014), and our observations of the biphasic peaks in the hemodynamic response in the current study. We computed the maximum haemodynamic activation for each load (1, 2, 3), trial type (same, different), chromophore ( $\mathrm{HbO}, \mathrm{HbR})$, channel ( 1 to 14$)$, and participant ( $N=74)$ during these early and late phase windows. These values were entered into further statistical analyses.

\section{Questionnaire Analyses:}

All questionnaire data were log-transformed to account for skewed distributions. These data were correlated with behavioural and brain measures. The Benjamini-Hochberg test was run for correlations between brain/behavioural measures and variables within each parental questionnaire scale separately with a false discovery rate of 0.25 . Individual $p$-values were ranked in ascending order, with 1 being the smallest $p$-value, 2 being the second smallest value, and so forth. We then calculated each individual $p$-value's critical $B H$ value using the following formula: $(i / m) Q$, where, $i=$ individual $p$ - 
HOME ASSESSMENT OF VISUAL WORKING MEMORY

value rank, $m=$ total number of tests, and $Q=$ false discovery rate of 0.25 . Finally, we compared our original $p$-values to the critical Benjamini-Hochberg value to find the highest $p$-value that was also smaller than the critical value. All correlations with $p$ values above this highest $p$-value were considered significant.

\section{Results}

Behavioural results:

We ran a repeated-measures ANOVA with a within-subjects factor of load to investigate how A' changed as a function of load, and if our findings were in agreement with previous work (Simmering, 2012). The main effect of load was significant ( $F[2$, $146]=90.37, p<0.001$, partial eta square $\left.\left(\eta_{p}^{2}\right)=0.301\right)$. Follow-up pairwise comparisons revealed that accuracy at load $1(M=0.96, S D=0.04)$ was greater than at load $2(M=0.86, S D=0.17, t[73]=5.29, p<0.001)$, and load $3(M=0.82, S D=0.13, t[73]$ $=9.5, p<0.001)$. Further, accuracy at load 2 was greater than accuracy at load $3,(t[73]$ $=2.27, p=0.026)-$ see Fig. 5 . These results were in agreement with findings from Simmering (2012).

Next, we applied median-splitting to the maximum $\mathrm{K}$ values to divide our participants into two performance groups: low-performers (LP) and high-performers $(\mathrm{HP})$. The median maximum $\mathrm{K}$ was 2 items, with 13 children performing at the median. We decided to include these 13 children into the HP group because their individual accuracy scores at load 3 fell above the median accuracy. This resulted in a total of $39 \mathrm{HPs}$ and $35 \mathrm{LPs}$. Figure 5(b) shows the mean maximum K estimates for HPs (2.4 \pm 0.06 items $)$ and LPs $(1.5 \pm 0.06$ items $)$.

\section{fNIRS Results:}

Four separate repeated-measures ANOVAs were run for the early and late phases, and $\mathrm{HbO}$ and $\mathrm{HbR}$ activation for each of the 14 channels. Each ANOVA included within-subject factors of load (1, 2 and 3 items) and trial type (same and different), and a between-subjects factor of group (HPs and LPs). Bonferroni correction was applied to the pair-wise comparisons in each of the ANOVAs. In the current study, we have 
HOME ASSESSMENT OF VISUAL WORKING MEMORY

focused only on significant effects for $\mathrm{HbO}$ activation. We have included the $\mathrm{HbR}$ results in Supplementary tables 2 and 3. However, we conducted t-tests to check if there was a significant difference between $\mathrm{HbO}$ and $\mathrm{HbR}$ activation in each channel to make sure that our effects were reliable $(p<.05)$. We found that there was a significant difference between $\mathrm{HbO}$ and $\mathrm{HbR}$ activation for every channel in the early phase, and all channels in the late phase except for channels 2, 4 and 8. Findings from these channels have been excluded. We have divided our findings into Groupgeneral effects (Load, Trial and Load $x$ Trial) and Group-specific effects (Group x Load, Group x Trial, Group x Load x Trial).

\section{Group-general HbO effects:}

All significant group-general effects are shown in Table 1. We have highlighted the main findings below. In the early phase, the main effect of load was significant in channel $3(F[2,144]=4.86, p=0.009)$, channel $5(F[2,144]=10.14, p<0.001)$, channel $6(F[2,144]=4.86, p=0.009)$, channel $7(F[2,144]=5.25, p=0.006)$, and channel 12 $(F[2,144]=3.30, p=0.04)$. Across these channels, activation at load 3 was greater than activation at load 1. Figure 6 shows the change in $\mathrm{HbO}$ activation with load for channel 6 . In the late phase, the main effect of load was significant in channel $5(F[2,144]=$ $9.89, p<0.001)$ and channel $6(F[2,144]=3.59, p=0.03)$. In both channels, activation at load 3 was greater than activation at load 1 .

\section{Group-specific HbO effects:}

All significant group-specific effects are shown in Table 2. Here, we highlight findings from the interaction between Group and Load, Group and Trial type. In the early phase, a significant interaction between Group and Load was observed in channel $1(F[2,144]$ $=3.31, p=0.039)$, channel $5(F[2,144]=4.30, p=0.015)$, channel $6(F[2,144]=6.99$, $p=0.001)$, channel $11(F[2,144]=4.34, p=0.015)$, channel $13(F[2,144]=3.28, p=0.04)$ and channel $14(F[2,144]=3.42, p=0.035)$. In channel 5 and channel 6 , LPs showed greater activation than HPs at load 3 . Further, in channel 5, channel 6, channel 11, channel 13 and channel 14, LPs elicited greater activation at load 3 than at load 1. Figure 7 shows the average $\mathrm{HbO}$ activation at each load for LPs and HPs in channel 
HOME ASSESSMENT OF VISUAL WORKING MEMORY

6. In the late phase, a significant interaction between Group and Load was observed in channel $6(F[2,144]=5.36, p=0.006)$ and channel $11(F[2,144]=3.18, p=0.044)$. In both channels, LPs elicited greater activation at load 3 than at load 1 . Thus, LPs showed a significant difference in activation between load 1 and load 3, whereas HPs did not show a difference in activation between loads.

A significant interaction between Group and Trial type was observed in the early phase in channel $2(F[1,72]=8.35, p=0.005)$. Specifically, HPs showed greater activation than LPs in the same trials, $(p=0.04)$. Further, HPs showed greater activation for same trials than for different trials, $(p=0.005)$. A significant interaction was also found in the late phase, $(F(1,72)=4.13, p=0.046)$. In channel 1 , HPs showed greater activation than LPs for same trials during the late phase $(p=0.018)$. Note that since the difference between $\mathrm{HbO}$ and $\mathrm{HbR}$ activation was not significant in channel 2 , the effects in this channel are ignored. In addition, there was no difference in the percentage of correct responses between same and different trials, so these effects have been ignored. However, they have been reported in Table 2.

Correlations between behavioural and brain measures and parental questionnaire data:

We averaged activation across channels that showed a significant Group x Load interaction to create four brain clusters as they showed the same trends. The four brain clusters were left frontal cortex, right frontal cortex, left parietal cortex and right parietal cortex. Next, we calculated the difference in activation between load 3 and load 1 in these brain clusters (for each participant) as this key measure differentiated LPs from HPs. Note that, as expected, the difference in activation between loads in all four brain clusters was negatively correlated with maximum $\mathrm{K}$, suggesting that this measure was still associated with performance when the latter is considered continuously (see Supplementary Fig. 1). This difference in activation in each of the four brain clusters was correlated with data from the parental questionnaires. For all correlations, we corrected for outliers by excluding values that were 3 standard deviations above or below the mean. Only those correlations that survived the outlier correction are reported and moved into further analyses. 
HOME ASSESSMENT OF VISUAL WORKING MEMORY

We found that maximum $\mathrm{K}$ was negatively correlated with the parenting tasks subscore from the Parent Daily Hassles scale ( $r=-0.262, p=0.024$, see Fig. 8a). We applied the Benjamini-Hochberg correction to 4 subscores with a false discovery rate of 0.25 . Parenting tasks refer to the tedious everyday jobs related to child-rearing, with a higher score indicating a greater number of such tasks. Concretely, parents who reported experiencing less bothersome parenting tasks had children with better VWM performance. Next, the difference in activation in the right parietal cortex was positively correlated with the life stress subscore from the Parenting Stress Index $(r=0.317$, $p=0.006$, see Fig. $8 b$ ). Here, we applied the correction to 17 subscores with a false discovery rate of 0.25 . Life stress in this scale refers to any major life event that significantly increases life stress. Additionally, we found that the difference in activation in the left frontal cortex was negatively correlated with the emotional problems subscore of the Strengths and Difficulties questionnaire $(r=-0.281, p=0.016$, see Fig. $8 c)$. We applied the correction to 9 subscores with a false discovery rate of 0.25 . The emotional problems subscore refers to issues relating to nervousness, clinginess, fearfulness, and unhappiness. Lastly, the difference in activation in the left parietal cortex was negatively associated with parental aspirations $(r=-0.377, p=0.001)$. Parental aspirations were measured as the highest qualification parents hoped their children would achieve.

\section{Mediation Analyses:}

We conducted mediation analyses to further understand the association between behaviour, brain activation, and data from parental questionnaires. In particular, we considered the difference in brain activation to be a potential mediator between distal predictors (as measured by parental questionnaires) and the outcome measure (maximum K). According to Shrout \& Bolger (2002), when a predictor is not experimental-based and distal in nature (e.g., home environment), an association between the predictor and the mediator is sufficient to warrant a test for mediation. Therefore, we focused on the previously identified significant bivariate relationships between life stress and the difference in activation in the right parietal cortex, parental aspirations and the difference in activation in the left parietal cortex, as well as emotional problems and the difference in activation in the left frontal cortex. 
HOME ASSESSMENT OF VISUAL WORKING MEMORY

We used the mediation function in $\mathrm{R}$ with bootstrapping for our analyses. We found that the difference in activation in the right parietal cortex partially mediated the relationship between life stress and maximum K (indirect path $=-0.1635, p=0.004$ ). The mediation effect remained significant after we controlled for both parental education and income $(p=0.006)$. Specifically, we found that higher life stress was related to a larger difference in activation in the right parietal cortex, which in turn was related to lower maximum K. Next, we found that the difference in activation in the left frontal cortex partially mediated the relationship between emotional problems in the children and maximum $\mathrm{K}$ (indirect path $=0.2454, p=0.008$ ). The mediation effect did not hold after we controlled for both parental education and income $(p=0.056)$. Lastly, we found that the difference in activation in the left parietal cortex did not partially mediate the relationship between parental aspirations and maximum $\mathrm{K}$ (indirect path $=0.302$, $p=0.078)$.

\section{Discussion}

VWM is an essential cognitive system with a highly limited capacity that is reliably predictive of future academic achievements making it important to understand the nature of individual differences in children (Bull et al., 2008; Swanson \& Berninger, 1996). Critically, it is important to try to fullfil this objective without the effect of varying age within the cohort as this might potentially drive individual differences in early development. In the current study, we investigate the association between behavior and brain activation in a VWM task, and the impact of the home environment, temperament and socioeconomic factors on key brain-behavior measures. We recorded behavioral and neural data from 4.5-year-old children with little variation in age as they completed a colour-change detection task in their homes. Overall, we found children's behavioural performance was consistent with Simmering (2012), with accuracy decreasing as load increased. Brain activation increased as load increased in four channels covering the bilateral frontal cortices. This finding is supported by previous fNIRS research conducted on three-year-old and four-year-old children, that found an increase in activation as load increased, with activation peaking at load 3 (Buss et al., 2014). Our results are also in agreement with the adult fMRI literature, which has consistently reported an increase in activation with increasing load in VWM 
HOME ASSESSMENT OF VISUAL WORKING MEMORY

(Jha \& McCarthy, 2000; Linden et al., 2003). The consistency between previous findings using the CCD task in a laboratory setting, and our results from conducting the same task in a home-setting, further validates this task as an effective way to measure VWM in children. Below, we expand further on our findings from low and high-performing children in the cohort.

Our first critical question was to investigate whether differences in behavioural performance would reveal differences in brain activation patterns. We found that LPs elicited more activation at load 3 than at load 1 in the bilateral frontal and parietal cortices. By contrast, the HPs showed no difference in activation between loads in any of the brain regions. In adults, there is mixed evidence for the relationship between behavior and brain activation. Nagel and colleagues (2009) examined performance differences in younger and older adults using a spatial working memory task. They reportd that young high performers showed increased activation with increasing load. Further, older low performers showed a drop in activation from loads 3 to 7 , wheras older high performers did not show this same trend. On the other hand, our results are supported by previous research in adults by Jaeggi et al (2007) who found that LPs compared to HPs showed large load-dependent increases in activation in the prefrontal cortex. They reported that the increase in activation observed in LPs represented a shift in the type and number of strategies employed. Honey and colleagues (2000) found that adults who performed more poorly on a verbal working memory task also showed increased activation in the bilateral posterior parietal cortex. They surmised that the increase in parietal activation could be reflective of an increase in attentional demands and the use of visuospatial strategies. However, it is unlikely that the low-performing pre-schoolers in our study employed such active procedural strategies, instead, an increase in activation might simply represent the passive recruitment of more neural resources to effortfully attend to the increasing demands of the task. A related explanation for the inverse relationship between behaviour and the difference in brain activation (low VWM performance linked to greater differences in activation) might be derived from a previous study conducted in rural India that used a preferential looking task to assess VWM processing in infants. Wijeakumar and colleagues (2019), found that infants with lower VWM performance showed greater activation in the bilateral dorsolateral prefrontal cortex (Fig. 9c). The authors suggested that greater activation in the frontal cortex might imply an inability to 
HOME ASSESSMENT OF VISUAL WORKING MEMORY

suppress distracting or irrelevant stimuli (the flashing non-changing display of the change preference task). The regions of interest identified in this effect in rural India sample overlapped with channel 1 in the right frontal cortex and channel 5 in the left frontal cortex in the current study (Fig. 9b). Taken together, we posit that the increase in activation might indicate the inability to supress distraction and/or the need to effortfully attend to the task to fulfill its objectives. Both accounts result in the reduction in efficiency, and by extension, poor VWM performance in LPs.

Our second critical question was to examine whether home environment, socioeconomic and temperament factors could shed light on the nature of the differences in behavioral measures and associated brain activation patterns. We found that more emotional problems in children were related to less difference in activation in the left frontal cortex, which in turn was related to increased behavioural performance. However, after controlling for parental income and education, this relationship did not hold. Thus, although a relationship might exist between VWM performance and emotional problems, it is largely dependent upon socioeconomic factors. In agreement with this finding, Herrmann and colleagues (2018) found that children from lower-income households scored higher on the emotional problems scale in the SDQ suggesting that family income contributes to parents' ability to invest in their child's social-emotional development.

We found that higher life stress was associated with a larger difference in activation in the right parietal cortex. Higher life stress was measured as a greater number of stressful life events including but not limited to, divorce, change in job/school, death of a family member, and substance abuse. This type of parental life stress negatively impacted children's performance on the task through the activation in the right parietal cortex. We posit that a greater number of stressful life events might cause instability in the child's life, resulting in changes to their cognitive processing, specifically for VWM processes that necessitate the need to hold multiple information, goals or rules. In a household environment with shiftting/shifted stability, it is possible that children are constantly distracted, and unable to consistently sustain attention or memory to efficiently accomplish goals or tasks. Hanson and colleagues (2012) assessed cumulative life stress in children and found that it negatively impacted working memory performance. We also found that increased difference in activation in the right parietal cortex was associated with a higher number of parent-reported 
HOME ASSESSMENT OF VISUAL WORKING MEMORY

daily hassles relating to child-rearing. These hassles refer to the stressful events that occur every day when raising children such as being interrupted, breaking up sibling fights, not being listened to, and continuously cleaning up. Taken together, we suggest that children who are exposed to a greater number of major stressful life events are constantly distracted and incur defecits in VWM processing. Futher, such cognitive defecits in goal-oriented tasks throughout the day might create more daily parental hassles. In agreement with this finding, a study that examined the behavioural and cognitive profiles of children identified as having working memory impairments found that teachers typically judged these children as being inattentive, easily distracted, and failing to remember instructions, thus disrupting classroom activities (Alloway et al., 2009).

In summary, we showed that LP children recruited more activation in the frontoparietal network in order to meet the increasing demands of the task, while, HP children did not show any difference in activation with increasing task difficulty. Further, we identified how different types of parent-reported stress including life stress and daily hassles negatively impacted children's VWM.

\section{References}

Aaronson, D., Watts, B., 1987. Extensions of Grier's Computational Formulas for A' and B" to Below-Chance Performance. Psychol. Bull. https://doi.org/10.1037/0033-2909.102.3.439

Abidin, R., Flens, J.R., Austin, W.G., 2013. The parenting stress index, in: Forensic Uses of Clinical Assessment Instruments. https://doi.org/10.4324/9780203726587 
HOME ASSESSMENT OF VISUAL WORKING MEMORY

Alloway, T.P., Alloway, R.G., 2010. Investigating the predictive roles of working memory and IQ in academic attainment. J. Exp. Child Psychol. https://doi.org/10.1016/j.jecp.2009.11.003

Alloway, T.P., Gathercole, S.E., Kirkwood, H., Elliott, J., 2009. The cognitive and behavioral characteristics of children with low working memory. Child Dev. https://doi.org/10.1111/j.1467-8624.2009.01282.x

Alloway, T.P., Seed, T., Tewolde, F., 2016. An investigation of cognitive overlap in working memory profiles in children with developmental disorders. Int. J. Educ. Res. https://doi.org/10.1016/j.ijer.2015.09.009

Ambrose, J.P., Wijeakumar, S., Buss, A.T., Spencer, J.P., 2016. Feature-based change detection reveals inconsistent individual differences in visual working memory capacity. Front. Syst. Neurosci. https://doi.org/10.3389/fnsys.2016.00033

Baddeley, A., 2003. Working memory: Looking back and looking forward. Nat. Rev. Neurosci. https://doi.org/10.1038/nrn1201

Boas, D.A., Elwell, C.E., Ferrari, M., Taga, G., 2014. Twenty years of functional near-infrared spectroscopy: Introduction for the special issue. Neuroimage. https://doi.org/10.1016/j.neuroimage.2013.11.033

Bull, R., Espy, K.A., Wiebe, S.A., 2008. Short-term memory, working memory, and executive functioning in preschoolers: Longitudinal predictors of mathematical achievement at age 7 years. Dev. Neuropsychol. https://doi.org/10.1080/87565640801982312

Bull, R., Scerif, G., 2001. Executive functioning as a predictor of children's mathematics ability: Inhibition, switching, and working memory. Dev. Neuropsychol. https://doi.org/10.1207/S15326942DN1903_3

Buss, A.T., Fox, N., Boas, D.A., Spencer, J.P., 2014. Probing the early development of visual working memory capacity with functional near-infrared spectroscopy. Neuroimage. https://doi.org/10.1016/j.neuroimage.2013.05.034

Christophel, T.B., Klink, P.C., Spitzer, B., Roelfsema, P.R., Haynes, J.D., 2017. The Distributed Nature of Working Memory. Trends Cogn. Sci. 
HOME ASSESSMENT OF VISUAL WORKING MEMORY

https://doi.org/10.1016/j.tics.2016.12.007

Courtney, S.M., Petit, L., Maisog, J.M., Ungerleider, L.G., Haxby, J. V., 1998. An area specialized for spatial working memory in human frontal cortex. Science (80-. ). https://doi.org/10.1126/science.279.5355.1347

Crnic, K.A., Booth, C.L., 1991. Mothers' and Fathers' Perceptions of Daily Hassles of Parenting across Early Childhood. J. Marriage Fam. https://doi.org/10.2307/353007

Crnic, K.A., Greenberg, M.T., 1990. Minor Parenting Stresses with Young Children. Child Dev. https://doi.org/10.1111/j.1467-8624.1990.tb02889.x

Farah, M.J., Shera, D.M., Savage, J.H., Betancourt, L., Giannetta, J.M., Brodsky, N.L., Malmud, E.K., Hurt, H., 2006. Childhood poverty: Specific associations with neurocognitive development. Brain Res.

https://doi.org/10.1016/j.brainres.2006.06.072

Ferreira, T. de L., Brites, C., Alves Salgado Azoni, C., Maria Ciasca, S., 2015.

Evaluation of Working Memory in Children with Attention Deficit/Hyperactivity Disorder. Psychology 06, 1581-1588.

https://doi.org/10.4236/psych.2015.613155

Fukuda, K., Vogel, E., Mayr, U., Awh, E., 2010. Quantity, not quality: The relationship between fluid intelligence and working memory capacity. Psychon. Bull. Rev. https://doi.org/10.3758/17.5.673

Funahashi, S., Chafee, M. V., Goldman-Rakic, P.S., 1993. Prefrontal neuronal activity in rhesus monkeys performing a delayed anti-saccade task. Nature. https://doi.org/10.1038/365753a0

Fuster, J.M., Alexander, G.E., 1971. Neuron activity related to short-term memory. Science (80-. ). https://doi.org/10.1126/science.173.3997.652

Gathercole, S.E., Pickering, S.J., Knight, C., Stegmann, Z., 2004. Working memory skills and educational attainment: Evidence from national curriculum assessments at 7 and 14 years of age. Appl. Cogn. Psychol. https://doi.org/10.1002/acp.934

Goodman, R., 1997. The strengths and difficulties questionnaire: A research note. J. 
HOME ASSESSMENT OF VISUAL WORKING MEMORY

Child Psychol. Psychiatry Allied Discip. https://doi.org/10.1111/j.14697610.1997.tb01545.x

Grier, J.B., 1971. Nonparametric indexes for sensitivity and bias: Computing formulas. Psychol. Bull. https://doi.org/10.1037/h0031246

Hanson, J.L., Chung, M.K., Avants, B.B., Rudolph, K.D., Shirtcliff, E.A., Gee, J.C., Davidson, R.J., Pollak, S.D., 2012. Structural variations in prefrontal cortex mediate the relationship between early childhood stress and spatial working memory. J. Neurosci. https://doi.org/10.1523/JNEUROSCI.0307-12.2012

Herrmann, J., Vogel, M., Pietzner, D., Kroll, E., Wagner, O., Schwarz, S., Müller, E., Kiess, W., Richter, M., Poulain, T., 2018. Factors associated with the emotional health of children: high family income as a protective factor. Eur. Child Adolesc. Psychiatry. https://doi.org/10.1007/s00787-017-1049-0

Honey, G.D., Bullmore, E.T., Sharma, T., 2000. Prolonged reaction time to a verbal working memory task predicts increased power of posterior parietal cortical activation. Neuroimage. https://doi.org/10.1006/nimg.2000.0624

Jaeggi, S.M., Buschkuehl, M., Etienne, A., Ozdoba, C., Perrig, W.J., Nirkko, A.C., 2007. On how high performers keep cool brains in situations of cognitive overload. Cogn. Affect. Behav. Neurosci. https://doi.org/10.3758/CABN.7.2.75

Jeynes, W.H., 2005. Effects of parental involvement and family structure on the academic achievement of adolescents. Marriage Fam. Rev. https://doi.org/10.1300/J002v37n03_06

Jha, A.P., McCarthy, G., 2000. The influence of memory load upon delay-interval activity in a working-memory task: An event-related functional MRI study. J. Cogn. Neurosci. https://doi.org/10.1162/089892900564091

Johnson, M.K., McMahon, R.P., Robinson, B.M., Harvey, A.N., Hahn, B., Leonard, C.J., Luck, S.J., Gold, J.M., 2013. The relationship between working memory capacity and broad measures of cognitive ability in healthy adults and people with schizophrenia. Neuropsychology. https://doi.org/10.1037/a0032060

Koenigs, M., Barbey, A.K., Postle, B.R., Grafman, J., 2009. Superior parietal cortex is critical for the manipulation of information in working memory. J. Neurosci. 
HOME ASSESSMENT OF VISUAL WORKING MEMORY

https://doi.org/10.1523/JNEUROSCI.3706-09.2009

Linden, D.E.J., Bittner, R.A., Muckli, L., Waltz, J.A., Kriegeskorte, N., Goebel, R., Singer, W., Munk, M.H.J., 2003. Cortical capacity constraints for visual working memory: Dissociation of fMRI load effects in a fronto-parietal network. Neuroimage. https://doi.org/10.1016/j.neuroimage.2003.07.021

Luck, S.J., Vogel, E.K., 1997. The capacity of visual working memory for features and conjunctions. Nature. https://doi.org/10.1038/36846

Matheny, A.P., Wachs, T.D., Ludwig, J.L., Phillips, K., 1995. Bringing order out of chaos: Psychometric characteristics of the confusion, hubbub, and order scale. J. Appl. Dev. Psychol. https://doi.org/10.1016/0193-3973(95)90028-4

Miller, E.K., Cohen, J.D., 2001. An Integrative Theory of Prefrontal Cortex Function. Annu. Rev. Neurosci. https://doi.org/10.1146/annurev.neuro.24.1.167

Nagel, I.E., Preuschhof, C., Li, S.C., Nyberg, L., Bäckman, L., Lindenberger, U., Heekeren, H.R., 2009. Performance level modulates adult age differences in brain activation during spatial working memory. Proc. Natl. Acad. Sci. U. S. A. https://doi.org/10.1073/pnas.0908238106

Pashler, H., 1988. Familiarity and visual change detection. Percept. Psychophys. https://doi.org/10.3758/BF03210419

Postle, B.R., 2006. Working memory as an emergent property of the mind and brain. Neuroscience. https://doi.org/10.1016/j.neuroscience.2005.06.005

Sato, H., Yahata, N., Funane, T., Takizawa, R., Katura, T., Atsumori, H., Nishimura, Y., Kinoshita, A., Kiguchi, M., Koizumi, H., Fukuda, M., Kasai, K., 2013. A NIRS$\mathrm{fMRI}$ investigation of prefrontal cortex activity during a working memory task. Neuroimage. https://doi.org/10.1016/j.neuroimage.2013.06.043

Shrout, P.E., Bolger, N., 2002. Mediation in experimental and nonexperimental studies: New procedures and recommendations. Psychol. Methods. https://doi.org/10.1037/1082-989X.7.4.422

Simmering, V.R., 2016. I. WORKING MEMORY CAPACITY IN CONTEXT: MODELING DYNAMIC PROCESSES OF BEHAVIOR, MEMORY, AND DEVELOPMENT. Monogr. Soc. Res. Child Dev. 
HOME ASSESSMENT OF VISUAL WORKING MEMORY

https://doi.org/10.1111/mono.12249

Simmering, V.R., 2012. The development of visual working memory capacity during early childhood. J. Exp. Child Psychol. https://doi.org/10.1016/j.jecp.2011.10.007

Studer-Luethi, B., Bauer, C., Perrig, W.J., 2016. Working memory training in children: Effectiveness depends on temperament. Mem. Cogn. https://doi.org/10.3758/s13421-015-0548-9

Swanson, H.L., Beebe-Frankenberger, M., 2004. The relationship between working memory and mathematical problem solving in children at risk and not at risk for serious math difficulties. J. Educ. Psychol. https://doi.org/10.1037/00220663.96.3.471

Swanson, H.L., Berninger, V.W., 1996. Individual differences in children's working memory and writing skill. J. Exp. Child Psychol. https://doi.org/10.1006/jecp.1996.0054

Todd, J.J., Marois, R., 2005. Posterior parietal cortex activity predicts individual differences in visual short-term memory capacity. Cogn. Affect. Behav. Neurosci. https://doi.org/10.3758/CABN.5.2.144

Todd, J.J., Marois, R., 2004. Capacity limit of visual short-term memory in human posterior parietal cortex. Nature. https://doi.org/10.1038/nature02466

Tsujimoto, S., Yamamoto, T., Kawaguchi, H., Koizumi, H., Sawaguchi, T., 2004. Prefrontal cortical activation associated with working memory in adults and preschool children: An event-related optical topography study. Cereb. Cortex. https://doi.org/10.1093/cercor/bhh030

Wijeakumar, S., Huppert, T.J., Magnotta, V.A., Buss, A.T., Spencer, J.P., 2017a. Validating an image-based fNIRS approach with fMRI and a working memory task. Neuroimage. https://doi.org/10.1016/j.neuroimage.2016.12.007

Wijeakumar, S., Kumar, A., M. Delgado Reyes, L., Tiwari, M., Spencer, J.P., 2019. Early adversity in rural India impacts the brain networks underlying visual working memory. Dev. Sci. https://doi.org/10.1111/desc.12822

Wijeakumar, S., Magnotta, V.A., Spencer, J.P., 2017b. Modulating perceptual 
HOME ASSESSMENT OF VISUAL WORKING MEMORY

complexity and load reveals degradation of the visual working memory network in ageing. Neuroimage. https://doi.org/10.1016/j.neuroimage.2017.06.019

Wijeakumar, S., Spencer, J.P., Bohache, K., Boas, D.A., Magnotta, V.A., 2015.

Validating a new methodology for optical probe design and image registration in fNIRS studies. Neuroimage 106, 86-100.

https://doi.org/10.1016/j.neuroimage.2014.11.022

Wilson, F.A.W., Scalaidhe, S.P.., Goldman-Rakic, P.S., 1993. Dissociation of object and spatial processing domains in primate prefrontal cortex. Science (80-. ). https://doi.org/10.1126/science.8316836

Wolfe, C.D., Bell, M.A., 2004. Working Memory and Inhibitory Control in Early Childhood: Contributions from Physiology, Temperament, and Language. Dev. Psychobiol. https://doi.org/10.1002/dev.10152 
HOME ASSESSMENT OF VISUAL WORKING MEMORY

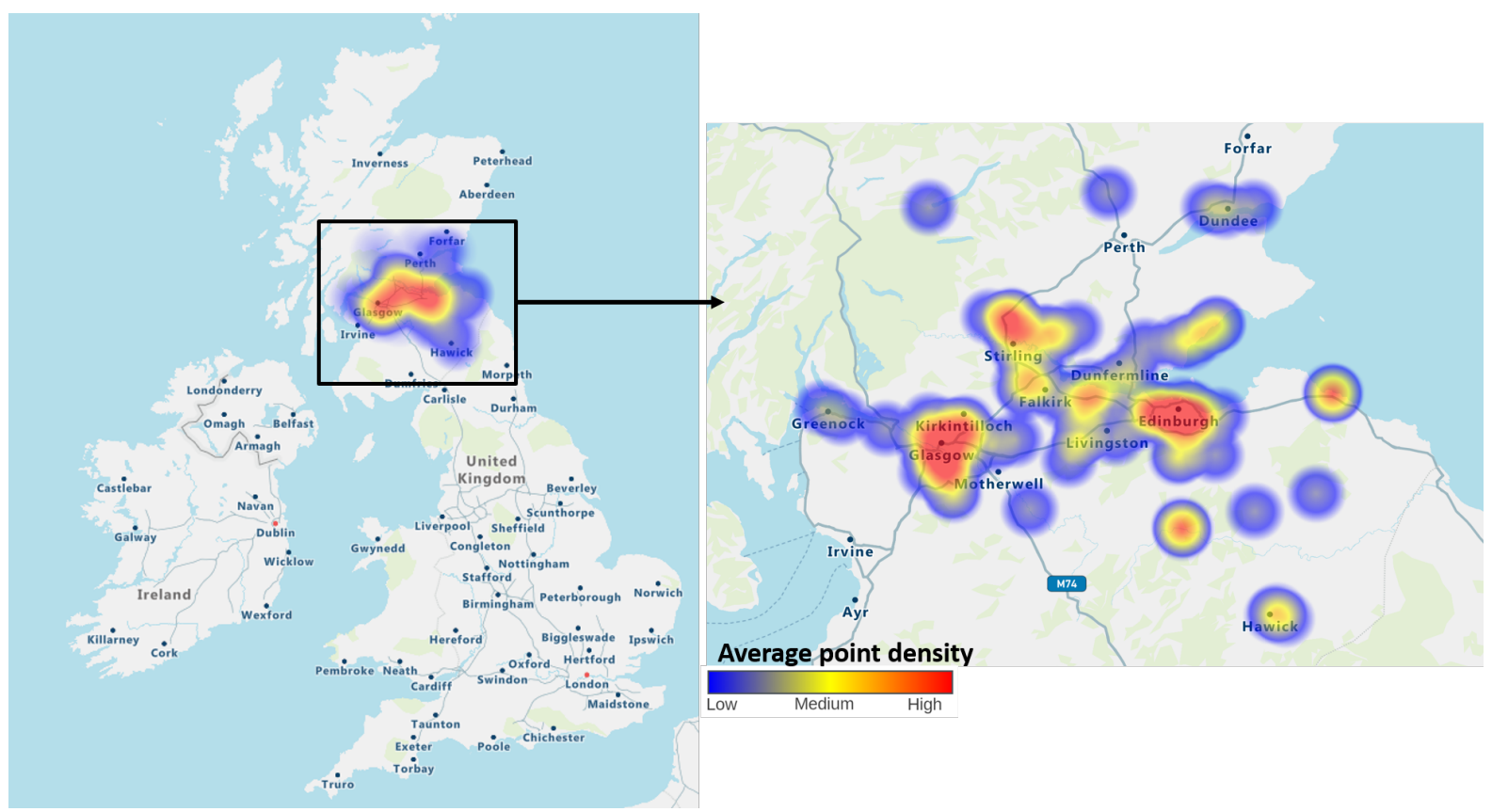

Fig. 1. Heatmaps showing geographic locations where the data was collected.

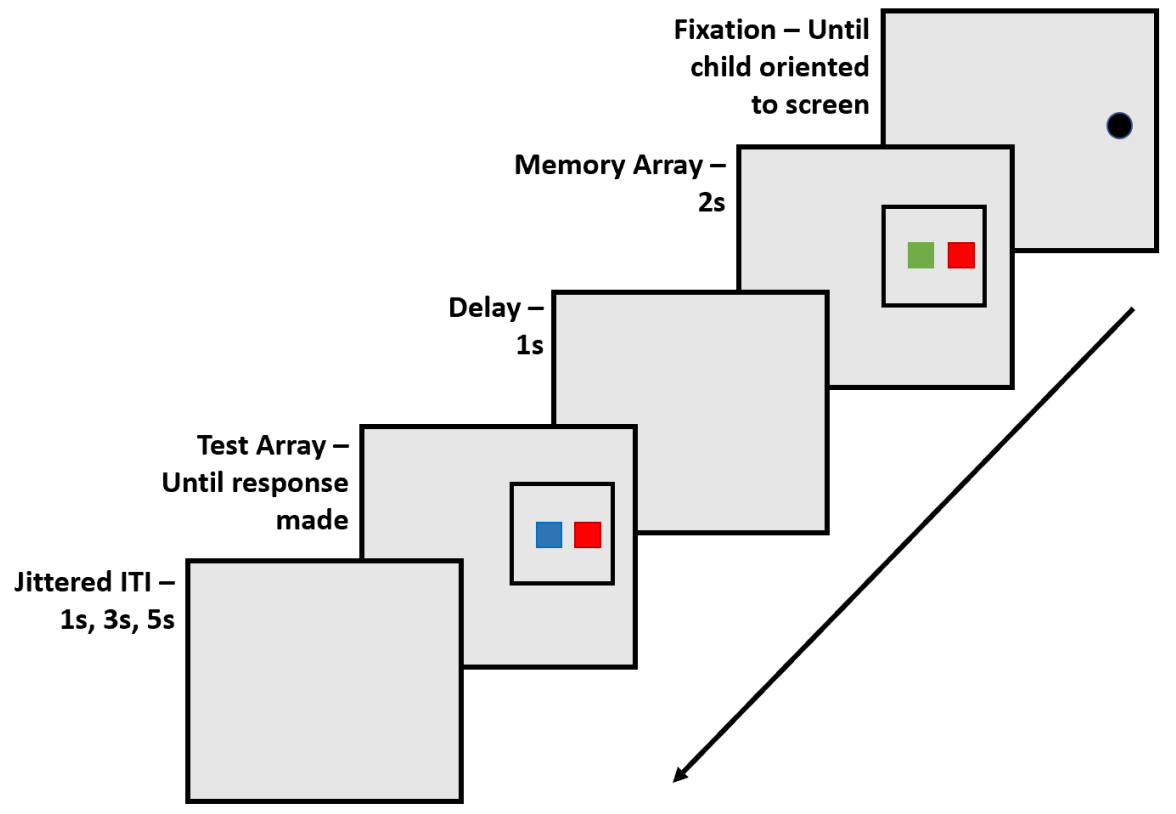

Fig. 2 Colour CD task - Load 2 different trial. 
HOME ASSESSMENT OF VISUAL WORKING MEMORY

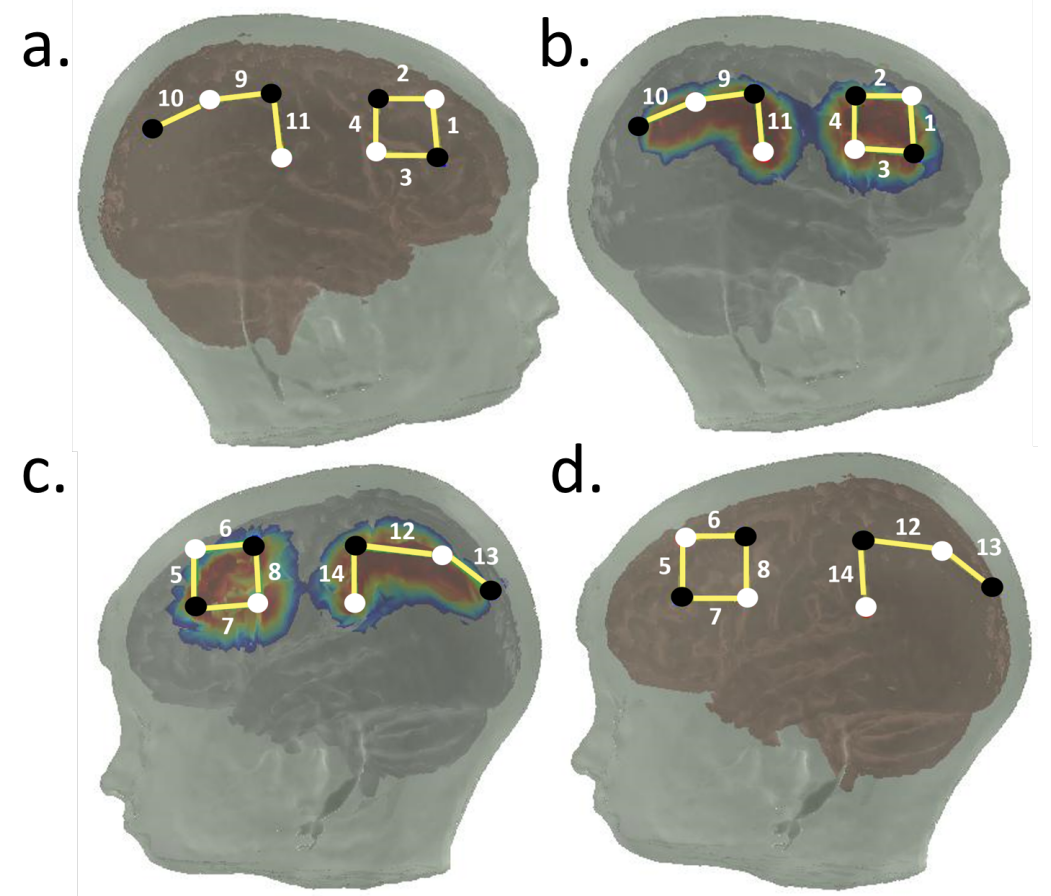

Fig. 3(a \& d) Probe geometry over the right and left hemispheres. The white circles represent the sources and the black circles represent the detectors. (b \& c) Sensitivity profiles after running Monte Carlo Simulations with 100 million photons.

a.

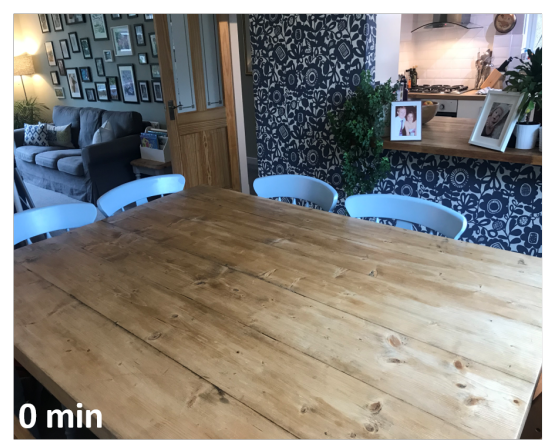

b.

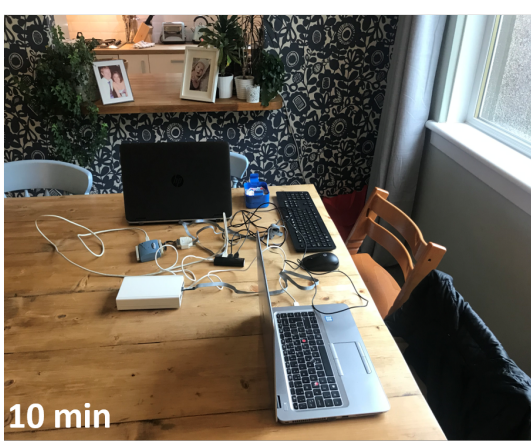

C.

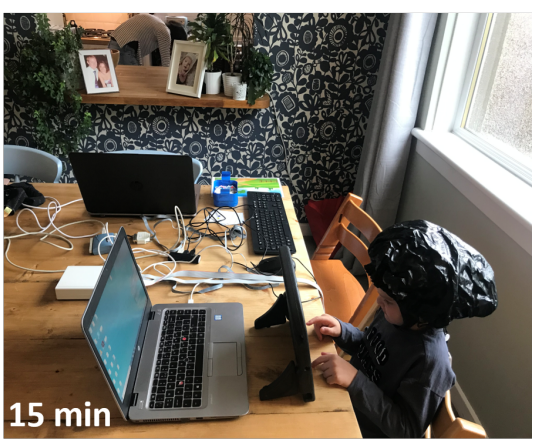

Fig. 4. Experimental set-up inside a participant's home. (a) Beginning of set-up (b) 10 minutes into set-up (c) Complete set-up after 15 minutes. 
HOME ASSESSMENT OF VISUAL WORKING MEMORY
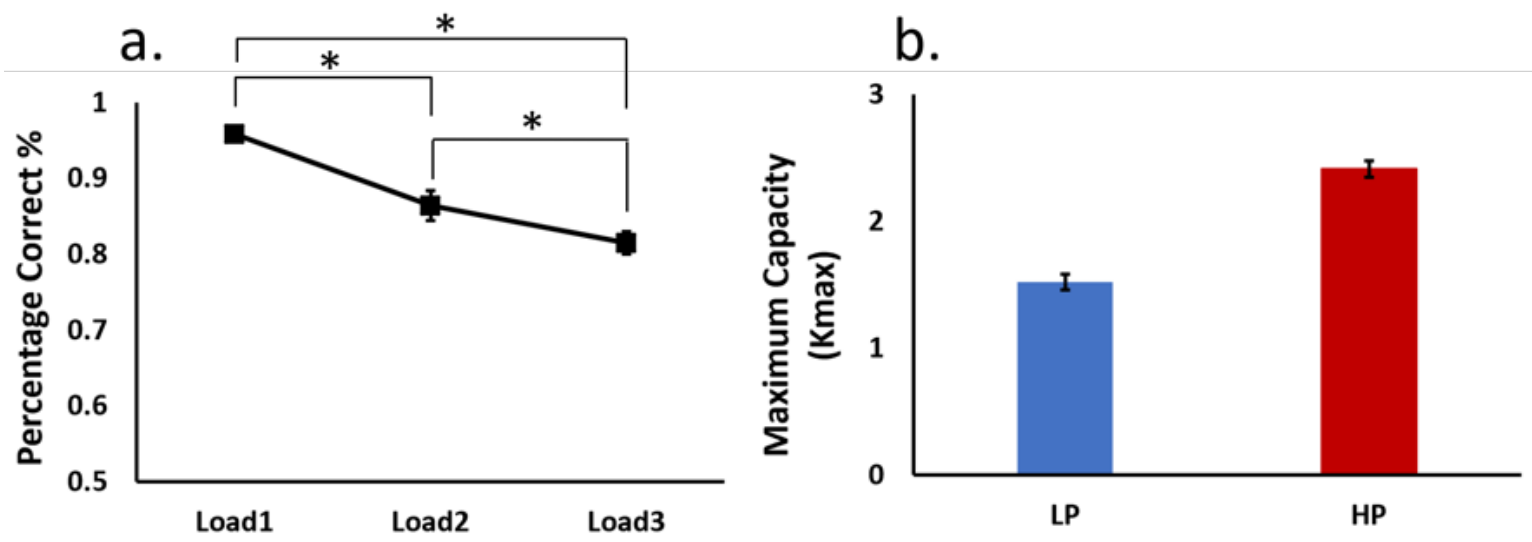

Fig. 5(a) A' decreased as load increased from 1 to 3 items. (b) Maximum $K$ estimates for high and low performers. Error bars show SEM.

Table. 1. Main effect of Load for $\mathrm{HbO}$ activation during the early and late phases.

\begin{tabular}{|c|c|}
\hline Channel No. & Load \\
\hline \multicolumn{2}{|c|}{ EARLY PHASE } \\
\hline \multirow{2}{*}{3 - Right frontal } & Load $3>$ Load $2(p=.033)$ \\
\hline & Load $3>$ Load $1(p=.02)$ \\
\hline \multirow{2}{*}{5 - Left frontal } & Load $3>$ Load $2(p=.001)$ \\
\hline & Load $3>$ Load $1(p=.001)$ \\
\hline 6 - Left frontal & Load $3>$ Load $1(p=.015)$ \\
\hline \multirow{2}{*}{7 - Left frontal } & Load $3>$ Load $2(p=.032)$ \\
\hline & Load $3>$ Load $1(p=.02)$ \\
\hline 12 - Left parietal & Load $2>$ Load $1(p=.049)$ \\
\hline \multicolumn{2}{|c|}{ LATE PHASE } \\
\hline \multirow{2}{*}{5 - Left frontal } & Load $3>$ Load $2(p<.001)$ \\
\hline & Load $3>$ Load $1(p=.004)$ \\
\hline 6 - Left frontal & Load $3>$ Load $1(p=.024)$ \\
\hline
\end{tabular}


HOME ASSESSMENT OF VISUAL WORKING MEMORY

a.

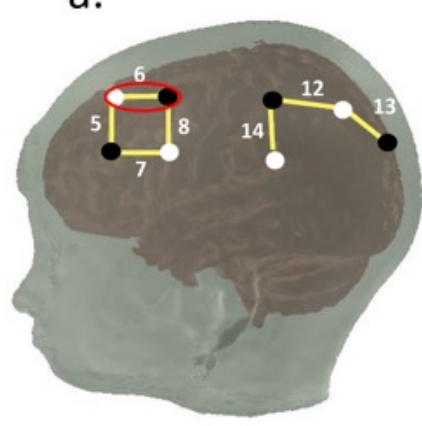

b.

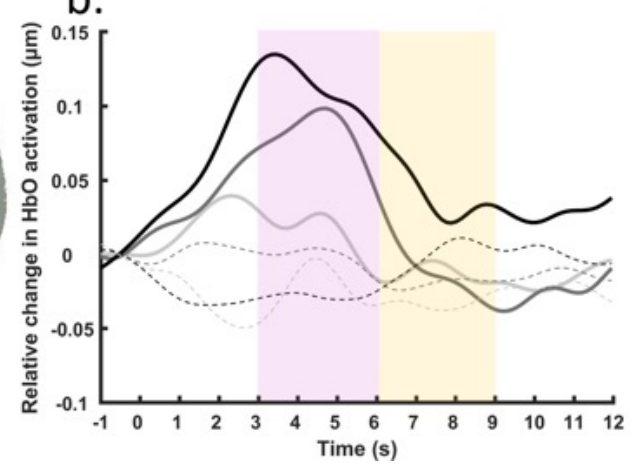

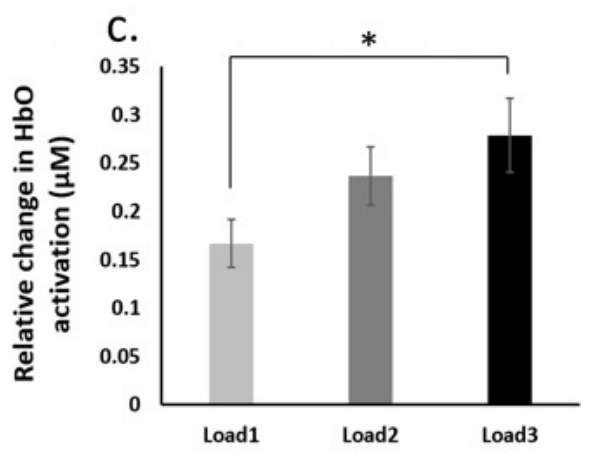

Fig. 6(a) Probe geometry showing channel 6 (circled in red). (b) $\mathrm{HbO}$ (solid lines) and $\mathrm{HbR}$ (dashed lines) activation for the early (magenta) and late (yellow) phases. Load 1 is shown in light grey, load 2 in dark grey, and load 2 in black. (c) Bar plot showing greater $\mathrm{HbO}$ activation at load 3 compared to load 1 for the early phase. 
HOME ASSESSMENT OF VISUAL WORKING MEMORY

Table. 2. Group-specific significant effects for $\mathrm{HbO}$ activation during the early and late phases. There was a significant difference between $\mathrm{HbO}$ and $\mathrm{HbR}$ activation for every channel in the early phase, and all channels in the late phase except for channels 2, 4 and 8.

\begin{tabular}{|c|c|c|c|}
\hline Channel No. & Group x Load & Group x Trial & Group x Load x Trial \\
\hline \multicolumn{4}{|c|}{ EARLY PHASE } \\
\hline 1 - Right frontal & LP: Load $3>$ Load $1(p=.003)$ & & \\
\hline 2 - Right frontal & & $\begin{array}{c}\text { Same: HP > LP }(p=.04) \\
\text { HP: Same }>\text { Different }(p=.005)\end{array}$ & $\begin{array}{c}\text { Load } 3 \text { Different: LP }>\text { HP }(p=.035) \\
\text { HP Load } 2 \text { Same }>\text { Different } \\
(p=.029) \\
\text { HP Load } 3 \text { Same }>\text { Different }(p=.03) \\
\text { LP Load 3: Different > Same } \\
(p=.016)\end{array}$ \\
\hline 5 - Left frontal & $\begin{array}{l}\text { Load 3: LP > HP }(p=.005) \\
\text { LP: Load } 3>\text { Load } 1(p<.001) \\
\text { LP: Load } 3>\text { Load } 2(p<.001)\end{array}$ & & \\
\hline 6 - Left frontal & $\begin{array}{l}\text { Load 3: LP > HP }(p=.025) \\
\text { LP: Load 3> Load } 1(p<.001) \\
\text { LP: Load } 3>\text { Load } 2(p=.044)\end{array}$ & & \\
\hline $\begin{array}{c}11 \text { - Right } \\
\text { parietal }\end{array}$ & $\begin{array}{l}\text { LP: Load } 3>\text { Load } 1(p=.007) \\
\text { LP: Load } 2>\text { Load } 1(p=.034)\end{array}$ & & \\
\hline 13 - Left parietal & LP: Load $3>$ Load $1(p=.036)$ & & \\
\hline 14 - Left parietal & LP: Load 3> Load $1(p=.041)$ & & \\
\hline \multicolumn{4}{|c|}{ LATE PHASE } \\
\hline 1 - Right frontal & & Same: HP > LP $(p=.018)$ & \\
\hline 2 - Right frontal & & Same: HP > LP $(p=.028)$ & \\
\hline 6 - Left frontal & $\begin{array}{c}\text { LP: Load } 3>\text { Load } 1(p<.001) \\
\text { Load } 3>\text { Load } 2(p=.023)\end{array}$ & & \\
\hline $\begin{array}{l}11 \text { - Right } \\
\text { parietal }\end{array}$ & $\begin{array}{l}\text { Load 1: HP > LP }(p=.047) \\
\text { LP: Load } 3>\text { Load } 1(p=.013)\end{array}$ & & \\
\hline
\end{tabular}



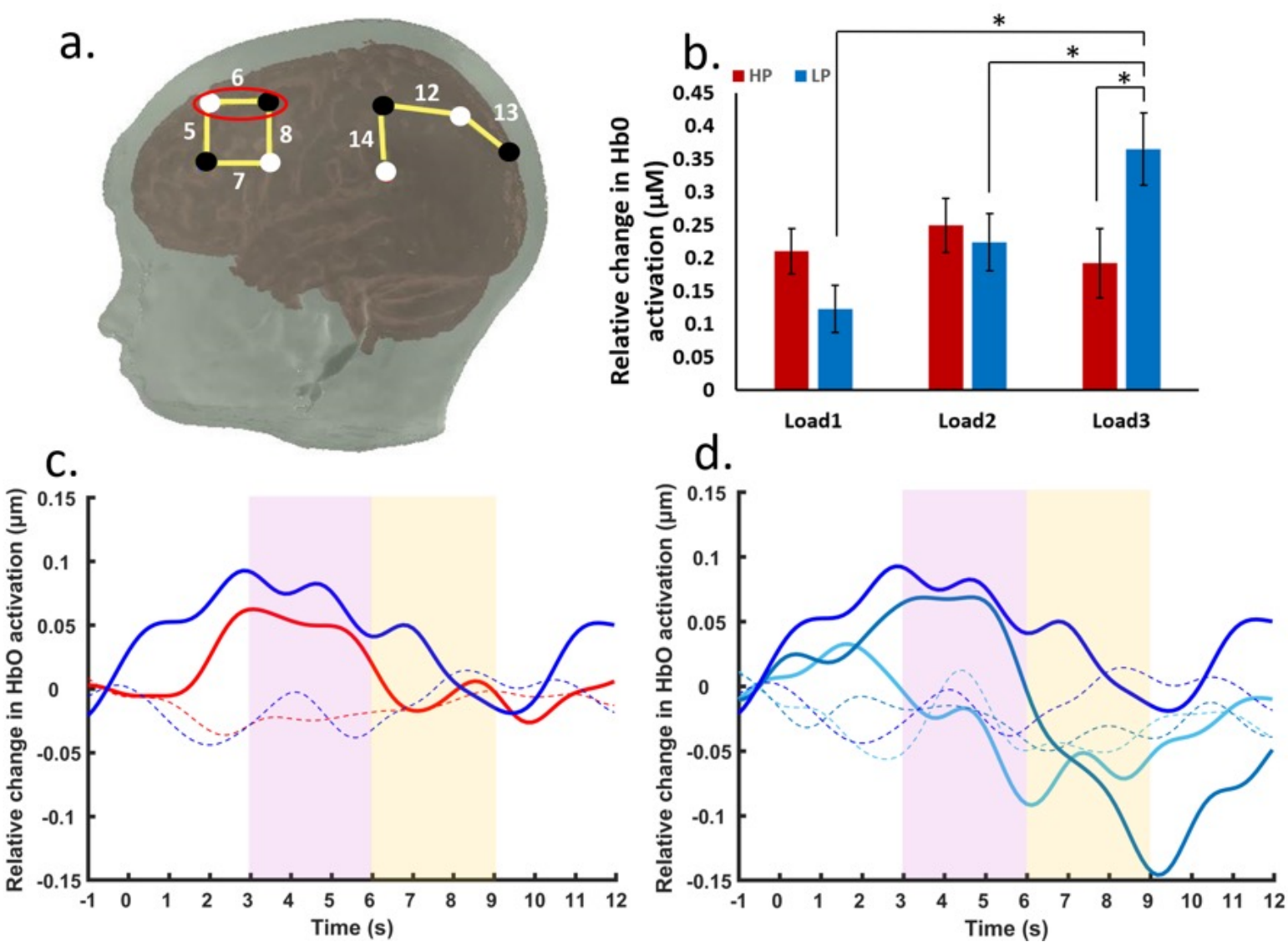

Fig. 7(a) Probe geometry showing channel 6 (circled in red). (b) Bar plot showing greater $\mathrm{HbO}$ activation for LPs (blue) compared to HPs (red) at load 3. In LPs, load 3 elicited greater HbO activation than load 2 and load 1. (c) $\mathrm{HbO}$ (solid lines) and $\mathrm{HbR}$ (dashed lines) activation for the early (shaded magenta) and late (shaded yellow) phases. (d) $\mathrm{HbO}$ (solid lines) and $\mathrm{HbR}$ (dashed lines) activation for the early (shaded magenta) and late (shaded yellow) phases. Load 1 is shown in light blue, load 2 in turquoise, and load 3 in dark blue.
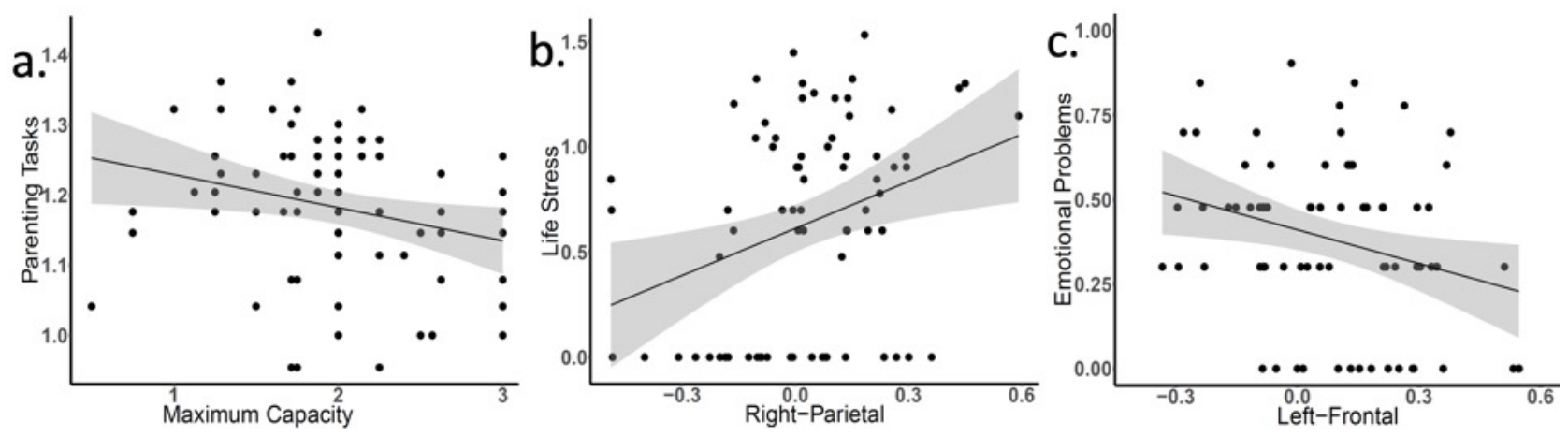

Fig. 8.(a) Plot showing a negative correlation between maximum $\mathrm{K}$ and the parenting tasks subscore of the Parenting Daily Hassles questionnaire. (b) Plot showing a positive correlation between the $\mathrm{HbO}$ difference in activation measure from the right parietal cortex and the life stress subscore of the Parental Stress Index. (c) Plot showing a negative correlation between 
HOME ASSESSMENT OF VISUAL WORKING MEMORY

the $\mathrm{HbO}$ difference in activation measure from the left frontal cortex and the emotional problems subscore of the Strengths and Difficulties Questionnaire.

a. Current Study Sample

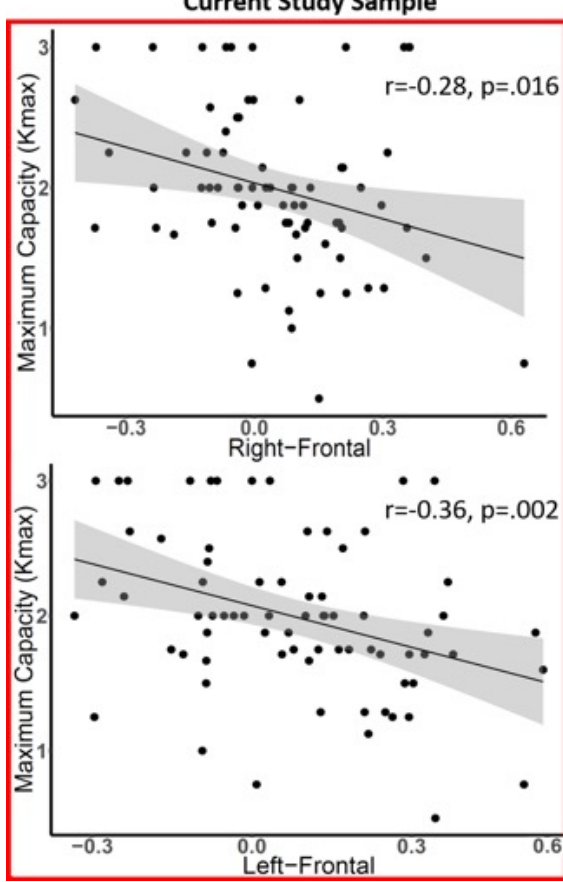

b. Overlap

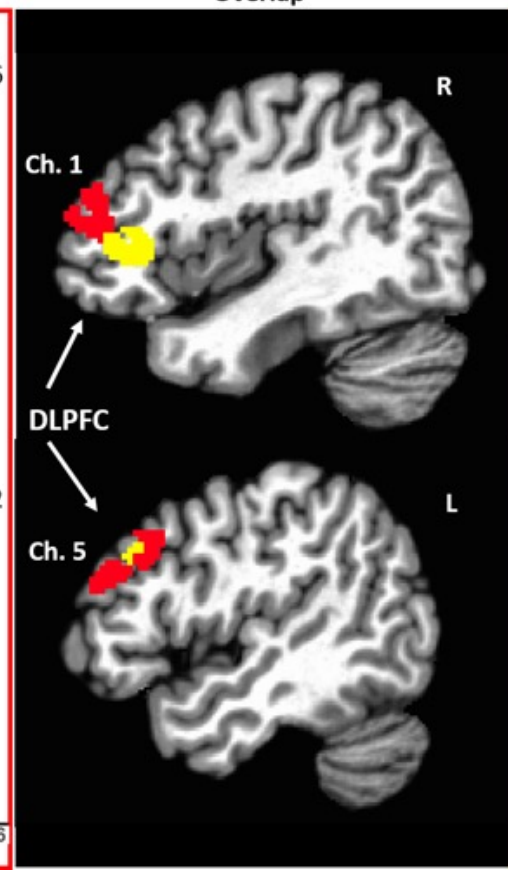

C.

Rural India Sample

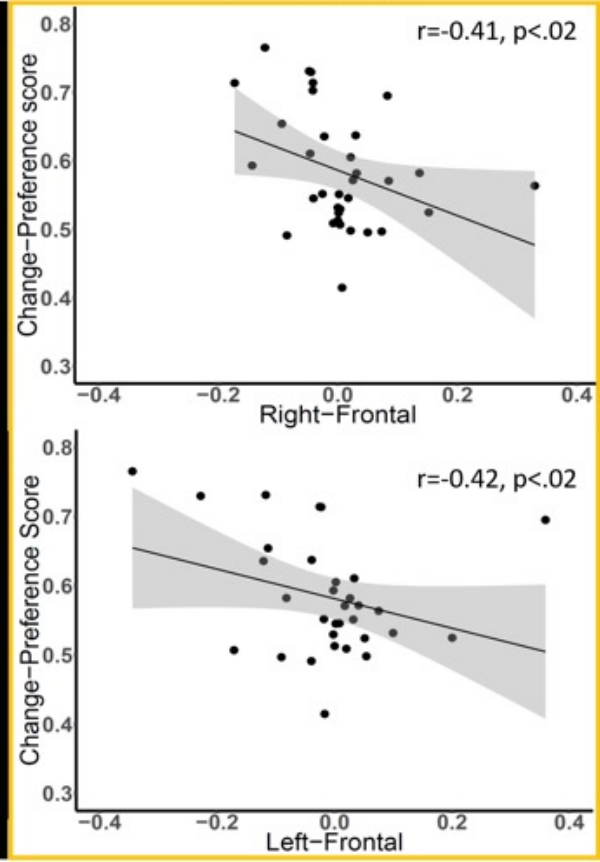

Fig. 9. (a) Correlation plots between maximum capacity estimates and $\mathrm{HbO}$ difference in activation measures for the right frontal (top) and left frontal (bottom) cortex in the current study sample. (b) Brain maps showing the overlap in activation between the current study sample (highlighted red) and the rural India sample (highlighted yellow). (c) Correlation plots between change-preference scores and relative change in $\mathrm{HbO}$ activation for the right frontal (top) and left frontal (bottom) cortex in the rural India sample. 